${ }^{6}$ Brown, M, and Glassenberg, M, Fournal of the American Medical Association, 1973, 224, 1493.

7 Denham, M J, Farran, H, and James, G, Age and Ageing, 1973, 2, 207.

${ }^{8}$ Frykholm, R, Surgery, Gynecology and Obstetrics, 1950, 71, 307.

${ }^{9}$ Greenstein, J, South African Medical fournal, 1945, 19, 350 and 377.

${ }^{10}$ Hunter, W C, et al, Surgery, 1945, 17, 178.

11 Gibbs, M M, British fournal of Surgery, 1957, 45, 209.

12 Sevitt, S, and Gallagher, N G, British fournal of Surgery, 1961, 48, 475.

${ }^{13}$ Roberts, G H, Scottish Medical fournal, 1963, 8, 11.

${ }^{14}$ Flanc, C, Kakkar, V V, and Clarke, M B, British fournal of Surgery, 1968, $55,742$.

15 Negus, D, et al, British fournal of Surgery, 1968, 55, 835.

${ }_{16}$ Murray, T S, et al, Lancet, 1970, 2, 792.

17 Hartsuck, J M, and Greenfield, L J, Archives of Surgery, 1973, 107, 733.
${ }^{18}$ Kakkar, V V, et al, Lancet, 1969, 2, 230.

19 Browse, N L, and Clemenson, G, British Medical fournal, 1974, 2, 468.

${ }^{20}$ Allenby, F, Jeyasingh, K, and Boardman, L, Lancet, 1973, 2, 199.

21 Sevitt, S, Lancet, 1972, 1, 145.

${ }^{22}$ Joy, W B, in $A$ System of Practical Medicine, ed A Tweedie, Vol 4, p 26. London, Whittaker, 1840.

${ }^{23}$ Virchow, R, Cellular Pathology, p 206. London, Churchill, 1858.

24 MacLachlin, J, and Paterson, J C, Surgery, Gynecology and Obstetrics, $1951,93,1$.

${ }_{25}$ Warlow, C P, and Ogston, D, Clinics in Haematology, 1973, 2, 199.

${ }^{26}$ Browse, N L, Clemenson, G, and Croft, D N, British Medical fournal, $1974,1,603$.

${ }^{27}$ Ruckley, C V, et al, Abstracts of Vth Congress of the International Society on Thrombosis and Haemostasis, Paris, 1975, p 228.

\title{
Psychiatric morbidity and the menopause: clinical features
}

\author{
C BARBARA BALLINGER
}

British Medical fournal, 1976, 1, 1183-1185

\section{Summary}

A sample of 114 women from the general population aged 40-55 years were identified as possible psychiatric cases and subjected to a standardised psychiatric interview. Mean ratings for reported symptoms and observed abnormalities were assessed in relation to menopausal status. There was no evidence of any specific combination of symptoms and signs associated with the cessation of menstrual periods, though after the menopause insomnia and hypochondriacal preoccupations were more common. In comparison with matched normal controls there was more likely to have been previous psychiatric illness, and contact with general practitioners was more frequent. Many women developing psychiatric symptoms at the time of the menopause appear to belong to a vulnerable population who are likely to develop symptoms in relation to stress.

\section{Introduction}

Opinions on psychiatric illness occurring at the time of the menopause differ widely. Malleson ${ }^{1}$ stated that emotional symptoms at this time were precipitated by oestrogen deficiency and should be treated with oestrogen preparations. She described the symptoms as having a specific menopausal quality, different from those of psychiatric or psychogenic illness.

There has also been discussion about the nature of affective illness at this time of life. Kraepelin" described a syndrome of "involutional melancholia," which he separated out from affective illness in general on the basis of age of onset and clinical features. The concept of involutional melancholia was not restricted to illness at the time of the menopause but applied to affective illness in both men and women in later life. Tait $e t a l,{ }^{3}$ in a study of women admitted to mental hospital for the first time between the ages of 40 and 55, were unable to find any evidence of a clinically distinct involutional type of illness or any relationship between the onset of the illness and the menopause. Nikula-Baumann, ${ }^{4}$ who studied affective illness in later life, concluded that an involutional type of affective illness could be

Royal Dundee Liff Hospital, Dundee DD2 5NF

C BARBARA BALLINGER, MRCP, DPM, lecturer in psychiatry

separated out on clinical grounds, but the mean age of onset o the illness was 56 years and usually it began several years after the menopause. The women in her study were said to have normal urinary gonadotrophin excretion but urinary oestrogen excretion less than in controls, although not significantly so.

In view of the variation in opinion about the clinical features of psychiatric illness at the time of the menopause, and in particular the claim that emotional symptoms and signs differ in some way from those occurring before the menopause, I decided to obtain detailed information on symptoms and signs in a group of women aged 40-55 years identified as possible psychiatric cases and to relate the findings to their menopausal status.

\section{Method}

As previously described, ${ }^{5} 760$ women from the general population aged 40-55 years were screened for psychiatric illness using the general health questionnaire. ${ }^{6}$ Women who scored 12 or more on the questionnaire were regarded as possible psychiatric cases and invited to attend for interview. A standardised psychiatric interview schedule ${ }^{7}$ was used that was developed for use in community surveys and has been used in general practice. ${ }^{8}$ Individual symptoms are rated on a five-point scale, 0 indicating absence of a symptom and 1 a habitual trait or borderline symptom. A rating of 2 or more indicates a definite morbid symptom of mild (rated 2), moderate (rated 3), or severe degree (rated 4). Manifest abnormalities observed during the interview are rated on a five-point scale immediately after the interview. An overall severity rating may also be made, 0 indicating no psychiatric illness and 1 mild or subclinical psychiatric illness. An overall rating of 2 or more indicates psychiatric illness of mild (rated 2), moderate (rated 3), or severe degree (rated 4).

A brief personal history was taken at the time of the interview, including information on relation with husband and any change in libido. Frequency of visits to the general practitioner, previous psychiatric illness, and prescribed medication were also noted for each woman. The same information was obtained for a group of women matched in respect of social class, menopausal status, and age who had obtained low scores on the general health questionnaire. These "non-cases" were used as normal controls.

\section{Results}

Out of 539 women who returned completed questionnaires 155 scored 12 or more; 11 of these had had a hysterectomy. Of the remaining 144 women, $114(79 \%)$ agreed to the interview and were classified according to four subgroups-premenopausal (53 women), menopausal (26 women), less than six years postmenopausal (21 women), and six or more years postmenopausal (14 women). ${ }^{5}$ 
OVERALL SEVERITY RATINGS

Altogether $18(15.8 \%)$ of the 114 women were rated $1,67(58.8 \%)$ were rated $2,28(24 \cdot 6 \%)$ were rated 3 , and $1(0.9 \%)$ was rated 4 . There was no significant variation in the distribution of overall ratings among the subgroups.

\section{DIAGNOSIS ACCORDING TO INTERNATIONAL CLASSIFICATION OF} DISEASES

Of the 96 women given an overall severity rating of 2 or more, 28 were diagnosed as having an affective psychosis, 44 a depressive neurosis, 18 an anxiety neurosis, 1 an obsessional neurosis, 1 a phobic anxiety neurosis, and 4 a personality disorder.

\section{REPORTED SYMPTOMS}

Of the 114 women, $78(68 \%)$ were rated 2 or more for depression, $77(68 \%) 2$ or more for anxiety, and $74(65 \%) 2$ or more for fatigue. Irritability was rated 2 or more in $58(51 \%)$ of the women, impaired concentration in $47(41 \%)$, and depersonalisation in $10(9 \%)$.

Somatic symptoms were rated 2 or more in $60(53 \%)$ of the women. The commonest somatic symptom was headache, which was reported by 51 women to have become more distressing recently. Gastrointestinal symptoms, including nausea, indigestion, and heartburn, were also common, and breathlessness and palpitations were reported occasionally. There was no significant association of any one of these symptoms with any particular subgroup.

Phobias were rated 1-that is, present but not causing much distress in the previous week or causing the patient to alter her activity-in 36 women and 2 or more in 10. Animal phobias were reported by 16 women, lift phobia by 13 , and phobia of heights by 11. Lift phobia presented particular problems for two women living in high-rise flats, and one woman with agoraphobia was completely housebound.

Obsessions were rated 2 or more in 19 women. The commonest symptom was checking work to the point of being unable to complete it. Six women were greatly distressed by obsessional thoughts and ruminations on death or violence. Fifty-six women were rated 1 for obsession - that is, tendencies falling short of the full definition of an obsessional symptom.

Reported symptoms in relation to subgroups (fig 1)-Only insomnia varied among the subgroups, and this will be discussed separately. ${ }^{9}$
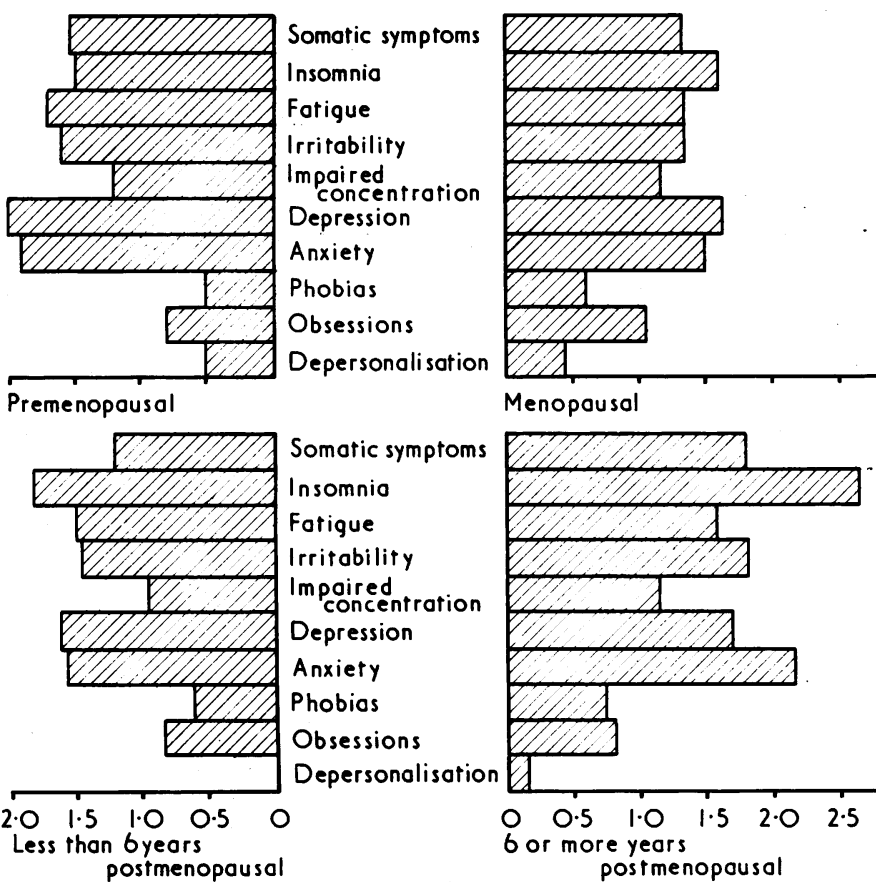

$\begin{array}{lllll}2.0 & 1.5 & 1.0 & 0.5 & 0 \\ \text { Less than byeors }\end{array}$ postmenopausal postmenopousol

FIG 1-Mean ratings for reported symptoms in relation to subgroup.

\section{MANIFEST ABNORMALITIES}

Anxiety, agitation, or tension was rated 2 or more in $94(82 \%)$ of the women, depression 2 or more in $62(54 \%)$ of the women, and depressive thoughts 2 or more in $44(39 \%)$ of the women. Excessive concern with body functions (hypochondriasis) was rated 2 or more in 40 women $(35 \%)$.

Manifest abnormalities in relation to subgroup (fig 2)-The only sign showing any significant variation among the subgroups was hypochondriasis. The mean rating of the combined premenopausal and menopausal subgroups for hypochondriasis was 0.83 , and the mean rating of the combined postmenopausal subgroups $1 \cdot 3$. This difference is significant $(t=2.35 ; \mathrm{DF}=112 ; \mathrm{P}<0.05)$. The possibility of having cancer was the commonest preoccupation, being present in $14(26 \%)$ of the premenopausal women, $4(15 \%)$ of the menopausal women, and $14(40 \%)$ of the postmenopausal women. The difference between the postmenopausal subgroups and the rest is not significant.
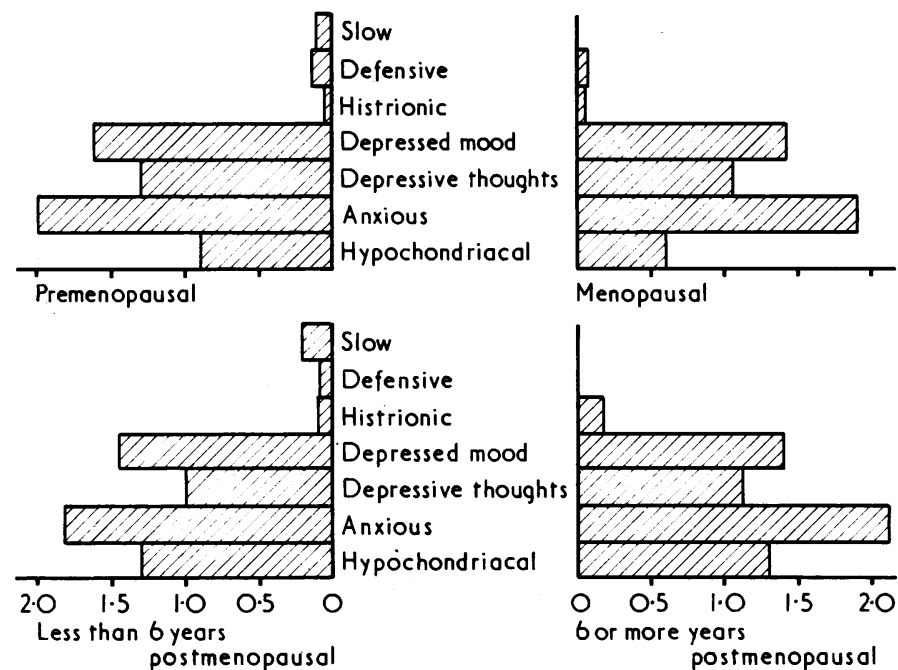

FIG 2-Mean ratings for observed abnormalities in relation to subgroup.

\section{LIBIDO AND MARITAL RELATIONS}

Thirty-four of the women complained of a recent deterioration in sexual responsiveness and five stated that interest in sexual relations had increased. Twenty-four women claimed that they had never enjoyed sexual intercourse and that there had been no recent change in their attitude; 27 women stated that sexual intercourse was satisfactory and that there had been no recent change. There was no significant variation in reports of change of libido among the subgroups. Five women had refused intercourse completely for five to 17 years. In one case this was precipitated by childbirth.

When asked to assess their relationship with their husbands on a three-point scale-good, fair, or poor-21 of the 90 women with husbands rated their relationship as poor, 25 as fair, and 44 as good. Twenty-three of the 58 women $(40 \%)$ who complained of persistently poor libido or a recent deterioration in libido rated their marital relationship as good, compared with $21(66 \%)$ of the 32 women stating that they had good or recently improved libido. This difference is significant $\left(\chi^{2}=4.64 ; \mathrm{DF}=1 ; \mathrm{P}<0.05\right)$.

\section{PREVIOUS CONTACT WITH PSYCHIATRIC SERVICES}

Eleven of the 155 women $(7 \cdot 1 \%$ ) who scored 12 or more on the general health questionnaire had had previous contact with the Dundee Psychiatric Services, compared with $8(2 \cdot 1 \%)$ of the 384 normal controls. This difference is significant $\left(\chi^{2}=6.6 ; \mathrm{DF}=1\right.$; $\mathrm{P}<0.05)$.

\section{CONTACT WITH GENERAL PRACTITIONERS}

Ninety-eight of the 114 women interviewed could be matched with 98 normal controls with regard to menopausal status, age, and social 
class. From 1 January 1973 to 31 December 1974 inclusive the mean number of visits to a general practitioner for the possible psychiatric cases was 13.4 and for the normal controls $7 \cdot 8$. This difference is significant $(t=4.3 ; \mathrm{DF}=97 ; \mathrm{P}<0.01)$.

Fifty-eight of the 98 possible cases and 20 of the controls had been prescribed hypnotics or other psychotropic drugs at least once in the previous five years $\left(\chi^{2}=29 \cdot 1 ; \mathrm{DF}=1 ; \mathrm{P}<0.001\right)$.

Forty-five of the possible cases and 26 of the controls had had evidence of an episode of anxiety or depression before $1970\left(\chi^{2}=7 \cdot 3\right.$ $\mathrm{DF}=1 ; \mathrm{P}<0.01)$. Thirty-five of the possible cases had made frequent visits to their doctors with symptoms of anxiety or depression, often termed "nervous debility," compared with five of the controls $\left(y^{2}=26.4 ; \mathrm{DF}=1 ; \mathrm{P}<0.001\right)$.

Fifteen of the possible cases and 17 of the controls had been prescribed oestrogen preparations within the previous five years.

\section{Discussion}

Of the 114 women identified from the general health questionnaire as being possible cases 18 were rated at the standardised psychiatric interview ${ }^{\top}$ as having no appreciable morbidity. This proportion of false-positives is similar to that reported by Goldberg and Blackwell ${ }^{8}$ (13 out of 102 possible cases), who used the same screening method.

The pattern of mean ratings for reported symptoms and manifest abnormalities (figs 1 and 2) was closely similar to that reported by Cooper ${ }^{10}$ for a group of chronic neurotic patients. The commonest reported symptoms were depression, anxiety, fatigue, and irritability. There was no significant variation in the mean ratings of these symptoms among the subgroups. Phobias and obsessions were much less common, but several women were considerably limited in their activities by phobias that they had never reported to their general practitioners.

Anxiety was the manifest abnormality most often given a rating of 2 or more by the observer. Depression of mood was the next most commonly observed phenomenon, followed by depressive thoughts and hypochondriasis. This last abnormality was the only one showing a significant change with menopausal status, being most common after the menopause. This finding was similar to that of Priest and Crisp, ${ }^{11}$ who found a peak at 45 to 54 years of age for the somatic category of the Middlesex Hospital questionnaire. This increase in preoccupation with bodily functions may be related to the change in somatic sensations at the time of the menopause, particularly the onset of flushes and sweats. The many reports of worry about cancer may also be related to anxiety about irregular bleeding and the cessation of periods.

The overall clinical picture was closely similar for all subgroups (figs 1 and 2). There was no evidence of any specific menopausal type of emotional disturbance as distinct from emotional disturbances occurring before the menopause. This finding is similar to that of Tait et $a l^{3}$ in relation to hospital admissions. In the study by Nikula-Baumann ${ }^{4}$ the clinical picture of an involutional type of illness was found in older people, and if it is accepted as a distinct clinical entity at all it does not appear to bear any relationship to the cessation of menstrual periods.

The classification of illness according to the International Classification of Diseases (1965) showed a preponderance of neurotic and affective illnesses. The combined figure for neurotic illness and personality disorder (69) far exceeded that for affective psychosis (27). In comparison, admissions of women to the local mental hospital in 1974 included 164 with an affective psychosis and 116 with a neurotic illness or personality disorder.

There is evidence ${ }^{11}$ of a gradual decrease in libido at the time of the menopause, and this continues with age. In this study information about change in libido was available only for the possible psychiatric cases, and among these women there was no evidence of any appreciable change in libido at or after the menopause. Many of these women expressed dissatisfaction with their sexual relations, and this group was significantly more likely to express dissatisfaction with their marital relationship as a whole. Both these complaints may be related to the problem that many neurotic patients have with interpersonal relationships in general.

It appeared that the women identified as having emotional problems made a considerable contribution to the work in general practice and were more likely to visit their general practitioners than those women who were not so identified. From the general practice notes at least $61 \%$ of the possible cases had been recognised as having primarily psychiatric problems to the extent of being treated at some time with psychotropic drugs. This again stresses the large involvement of the general practitioner with the management of emotional disturbance, as discussed by Goldberg and Blackwell. ${ }^{8}$

The women identified as possible psychiatric cases were significantly more likely to have had previous contact with the local psychiatric services or to have had a pervious episode of illness identified as psychiatric in nature by the general practitioner. In a previous study ${ }^{5}$ I showed that the proportion of possible psychiatric cases increased before the menopause and decreased immediately afterwards. This is a vulnerable group of women in that they are more likely to have developed some psychiatric symptoms in the past and to have again developed symptoms in relation to the psychological and perhaps physiological stresses occurring before and during the year of the menopause.

I thank Drs Jean Ferguson, John Ferguson, E D B Denovan, J B Malcolm, W H Gossip, and Carol Henderson for permission to approach their patients, and Professors I R C Batchelor and James Walker for advice and help in the preparation of this paper.

\section{References}

${ }^{1}$ Malleson, J, Lancet, 1953, 2, 158.

2 Kraepelin, E, Psychiatrie: Ein Lehrbuch fur studierende unde Arzte, 5th edn. Leipzig, Barth, 1896.

3 Tait, A C, Harper, J, and McClatchey, W T, fournal of Mental Science, 1957, 103, 132.

${ }^{4}$ Nikula-Baumann, L, Acta Psychiatrica Scandinavica, 1971, suppl No 226.

5 Ballinger, C B, British Medical fournal, 1975, 3, 344.

6 Goldberg, D P, The Detection of Psychiatric Illness by Questionniare. London, Oxford University Press, 1972.

' Goldberg, D P, et al, British fournal of Preventive and Social Medicine, $1970,24,18$.

8 Goldberg, D P, and Blackwell, B, British Medical fournal, 1970, 3, 439.

9 Ballinger, C B. In preparation.

10 Cooper, B, Proceedings of the Royal Society of Medicine, 1972, 65, 509.

11 Priest, R G, and Crisp, A H, in Psychosomatic Medicine in Obstetrics and Gynaecology, p 605. Basle, Karger, 1972. 